\title{
PROPOSAL OF GENERATION-TYPE TMD WITH ELECTROMAGNETIC DAMPING DEVICE AND ITS APPLICATION TO AN ACTUAL BRIDGE UNDER SERVICE
}

\author{
Hiroshi IWABUKI ${ }^{1}$, Eiichi SASAKI ${ }^{2}$, Koichi TAKEYA ${ }^{3}$, Toshikazu OSAFUNE ${ }^{4}$ \\ and Hideaki YASUDA 5 \\ ${ }^{1}$ Member of JSCE, Nippon Expressway Research Institute Company Limited \\ (1-4-1 Tadao, Machida-shi, Tokyo 194-8508, Japan) \\ E-mail: h.iwabuki.aa@ri-nexco.co.jp \\ ${ }^{2}$ Member of JSCE, Associate Professor, School of Environment and Society, Tokyo Institute of Technology \\ (M1-23 2-12-1 Ookayama, Meguro-ku, Tokyo 152-8552, Japan) \\ E-mail: sasaki.e.ab@m.titech.ac.jp \\ ${ }^{3}$ Member of JSCE, Assistant Professor, Integrated Graduate School of Engineering, University of Yamanashi \\ (4-4-37 Takeda, Kofu City, Yamanashi 400-8510, Japan) \\ E-mail: ktakeya@yamanashi.ac.jp \\ ${ }^{4}$ Member of JSCE, Central Nippon Expressway Company Limited \\ (2-18-19 Nishiki, Naka-ku, Nagoya City, Aichi 460-0003, Japan) \\ E-mail: t.osafune.aa@c-nexco.co.jp \\ ${ }^{5}$ Non-member, Central Nippon Highway Engineering Tokyo Company Limited \\ (1-23-7 Nishishinjuku, Shinjuku-ku, Tokyo 160-0023, Japan) \\ E-mail: yasuda@ri-nexco.co.jp
}

\begin{abstract}
In this study, a power generation-type Tuned Mass Damper (TMD) with an electromagnetic damping device that enables power generation and easier damping adjustment is proposed as an alternative to the conventional TMD with oil dampers installed on expressway bridges in service. A road traffic vibration test on an actual bridge in service was carried out to verify its damping effect and effect on reducing lowfrequency noise. Numerical simulations were carried out to show that by changing the electric resistance of the electromagnetic damping device, various types of power-generating TMDs can be designed, which focus on vibration control, energy absorption or power generation. In the experiment, using an actual bridge, the damping effect of the power generation-type TMD was confirmed to, on the whole, agree with the numerical simulation and the electric resistance design was proven to be useful. The results indicates that it is possible to use the power generation-type TMD, with the same level of damping effect as that of the oil damper, on an actual bridge.
\end{abstract}

Key Words : tuned mass damper (TMD), low-frequency noise, bridge-vibration, real bridge experiment

\section{INTRODUCTION}

In recent years, environmental problems along expressways caused by low-frequency noise emitted from bridges have been reported, and their causes and remedies are now under study. Tokunaga et al. ${ }^{1)}$ analyzed frequency characteristics of low-frequency noise emitted from road bridges, carried out field studies, and found that the primary mode of vertical vibration on bridges had a high correlation with the reciprocal of span length. Kawada and Kawatani ${ }^{2)}$ replicated the acoustic characteristics of the actual sound field and confirmed the effects of countermeasures, applying theoretical analysis of low-frequency noise using the boundary element method. Countermeasures for low-frequency noise from road bridges were studied and reported by Osafune, Yamamoto $^{3)}$ and Fukada ${ }^{4)}$.

Tuned Mass Damper (TMD) and Impact Mass Damper (IMD) are countermeasure technologies for low-frequency noise. In this system, weight, or mass, is added to the bridge through dampers and springs to control vibration. And by adjusting the weight of the mass and the rigidity of dampers and springs, the sys- 
tem restrains bridge-vibration by best tuning the eigenfrequency and damping. A past study ${ }^{5}$ proved that the system was useful in minimizing bridge-vibration and generation of low-frequency noise, and the system has been installed and is in operation on expressway bridges throughout Japan. However, inspections of TMDs have not been carried out after they were installed, which has been an issue. Followings have been reported in past studies: (a) The vibration frequency and damping constant of a bridge change over the years it is in service ${ }^{6}$, (b) the eigenfrequency change as gaps in concrete structures develop ${ }^{7)}$ and (c) vibrations from large-vehicles, amplified by running over rugged road surfaces are coupled with bridge-vibration, causing cyclic road surfaces, and this changes the vibration characteristics ${ }^{8)}$. Since bridge eigenfrequency and damping constant change over the years due to the aging of pavement, floor slabs, and other members, it is necessary to reset TMDs to the target frequency and damping ratio. Therefore, TMDs need to be easy to adjust, and be preferably equipped with a monitoring system to check frequency and damping.

Many methods to best control vibration using TMDs have been proposed. The following designs with a wider bandwidth in the target frequency have been proposed. Abe and Fujino ${ }^{9), 10)}$ offered a design method using Multiple Tuned Mass Damper (MTMD) that has an eigenfrequency of many tuned mass dampers, which are distributed within a certain bandwidth around the eigenfrequency of the target structure. Yoshinaka and Kawaguchi ${ }^{11)}$ proposed a dispersed TMD that controls multiple modes. However, they are hard to introduce to the single mass point $\mathrm{TMD}^{3), 5)}$ installed on many road bridges.

Therefore, the authors focused on adjusting the damping ratio of the TMD. One approach was to use the two mass point generation-type Tuned Mass Generator $(\mathrm{TMG})^{12)}$ that replaces the oil damper of the TMD, which we have designed, with an electromagnetic damping device and controls damping with the resistance of the electric circuit. TMG parameters can be changed easily, so designing it to control vibration or for vibration-powered generation is possible by changing the electric resistance of the electromagnetic damping device. The study in reference 12) aimed at power generation and designed and carried out verification tests of the two mass point TMG with $104 \mathrm{~kg}$ main mass and $12 \mathrm{~kg}$ sub mass. Since replacing oil dampers with electromagnetic damping devices is easy, it is expected that this method may be applied to TMDs with single mass point systems and mass weight of $1,500 \mathrm{~kg}$ class, which are widely installed on expressway bridges to control bridge-vibrations.

In this study, we replaced the single mass point TMD of about $1 \%$ mass ratio with an oil damper, which is installed on expressway bridges in service as an environmental measure, with a generation-type TMD with electromagnetic damping devices. We verified that its performance was equal to that of the single mass point TMD. We also conducted traffic vibration tests on an actual bridge in service to find out the generation-type TMD's damping effect, lowfrequency noise reduction, and amount of power generation. Prior to the tests, TMDs focusing on (a) reduction of peak vibration, (b) energy absorption, and (c) power generation were designed and the most suitable electric resistance for each type was calculated. To compare three types of data taken with different traffic volumes, bridge-vibration damping effects and low-frequency reduction effects were analyzed by standardizing the traffic volume of large-vehicles that very much contribute to bridge-vibration. By doing so, we clarified the parameters needed to dampen bridge-vibration by proposing an electromagnetic damping device for generation-type TMD and verified the reduction effects of bridge-vibration and low-frequency noise by testing on an actual bridge.

\section{BRIDGE USED IN THE TEST}

We designed a generation-type TMD with electromagnetic damping devices to replace TDMs using oil dampers that are installed on expressway bridges in service. To validate its damping effect and power generation, an actual bridge in service, where vehicles running on the bridge provided constant vibration, was selected for the test.

\section{(1) Outline of bridge used in the test}

The test was conducted on a 4-main plate girder steel bridge $(L=35 \mathrm{~m})$ with a simple structure using simple girders. The bridge was equipped with TMDs. The superstructure was reinforced with three vertical reinforcing girders, one between each main girder. A general drawing of a bridge is shown in Fig.1. The bridge was located near a residential area, so $4 \mathrm{~m}$-high noise barriers and backside acoustical boards under the main girders were installed. Fig.2 illustrates of the environmental measures. Since low-frequency noise around the test bridge caused by bridge-vibration was creating environmental problems, three TMDs were installed, one between each main girder, to minimize the problem. This TMD was designed to counter the first mode of bridge-vibration, and its specifications are shown in Table 1, installation location in Fig.3, and detail drawing in Fig.4. The bridge used for the test was equipped with the same type and same number of TMDs on both the inbound and outbound lanes. However, the tests were carried 


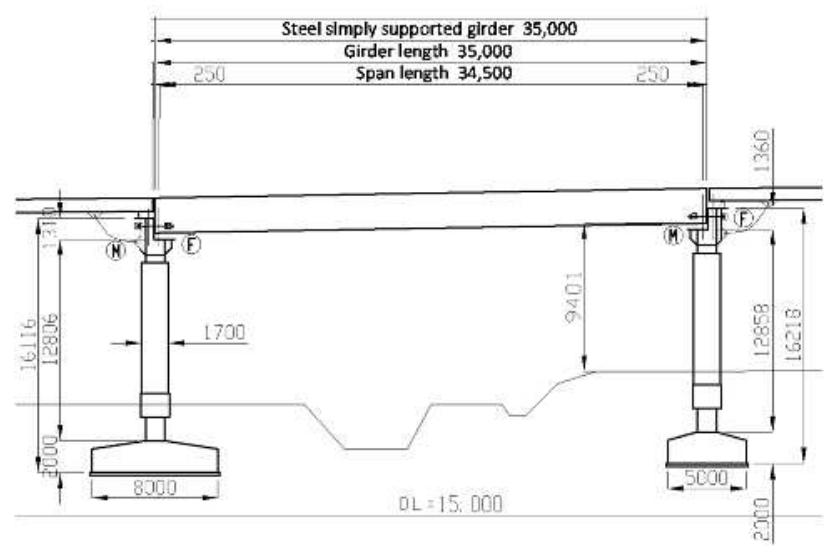

Fig.1 General drawing of bridge.

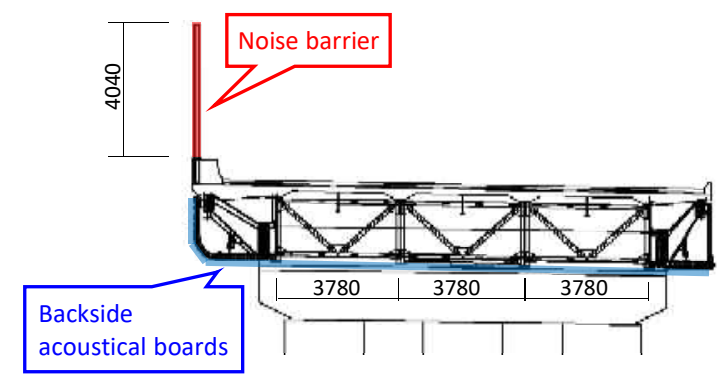

Fig.2 Environmental measures (Noise barrier and backside acoustical board).

Table 1 TMD specifications

\begin{tabular}{cc}
\hline Mass(per unit) & $1,500 \mathrm{~kg}$ \\
\hline Eigenfrequency & $3.45 \mathrm{~Hz}$ \\
\hline Damping ratio & $4.2 \%$ \\
\hline
\end{tabular}

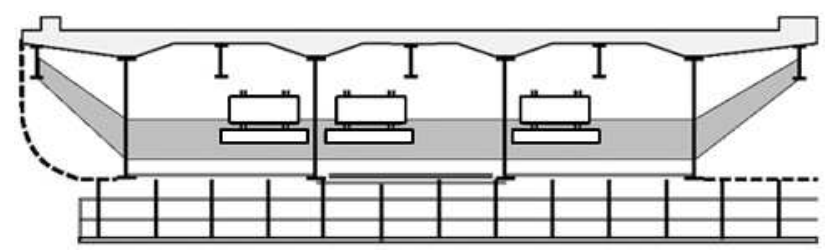

Fig.3 Position of TMD.

out on the inbound lanes where a traffic counter was installed nearby.

\section{(2) Vibration characteristics of the bridge used in the test}

First, to find out the bridge's vibration characteristics with the TMDs installed, we measured the vibrational acceleration and pressure level of the low-frequency noise. A layout of the sampling points is shown in Fig.5. To analyze frequency characteristics and prepare vibration modes, vibrational acceleration was measured at five points, including two at the end of the main girder span, one at the center of span, and two at $1 / 4$ from the end of span, using a piezoelectrictype vibration level meter (Rion VM-53). The pressure level of the low-frequency noise was measured at the center of span $1.2 \mathrm{~m}$ high on the acoustical board, using a vibration-level meter (Rion LN-62).

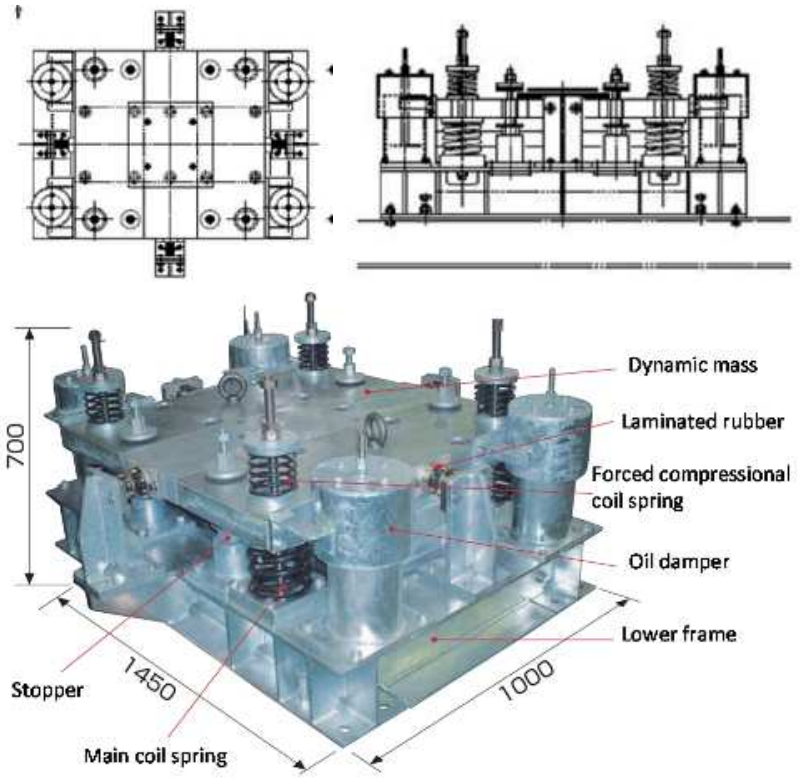

Fig.4 Configuration and dimensions of installed $\mathrm{TMD}^{13)}$.

$\leftarrow$ Vehicle direction

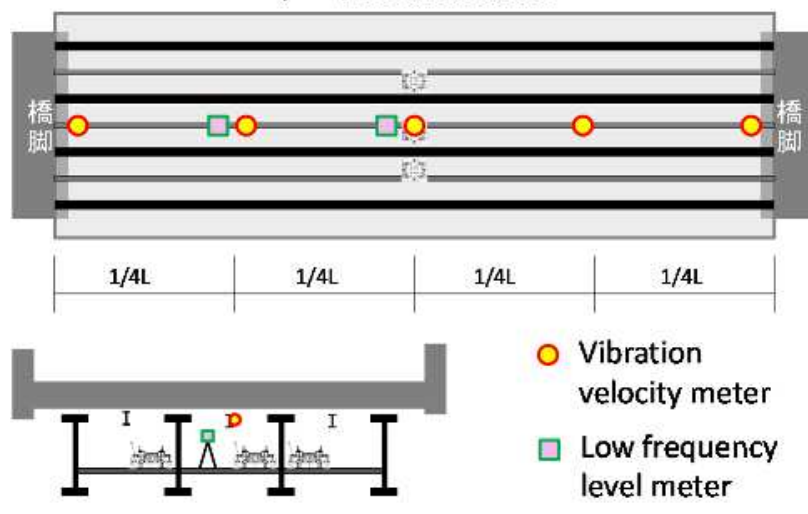

Fig.5 Sampling point layout.

Generally, pressure levels of low-frequency noise are measured at $1.2 \mathrm{~m}$ high from the ground. But because this test was meant to evaluate the vibration characteristic of the inbound lanes only, the noise pressure level was measured from the backside acoustical board, where noise from the outbound lanes would not affect the measurement. Vibrational acceleration and low-frequency noise pressure level were simultaneously recorded by a data recorder (Rion DA-21) at a sampling frequency of $256 \mathrm{~Hz}$. Sample measurements were taken with all three TMDs (a) in operation and (b) not in operation. The results of the FFT analysis for vibrational acceleration at the $1 / 2$ point of the main girder span are shown in Fig. 6 and the vibration mode for the dominant frequency in Fig.7. Fig.6 shows the results of the analysis carried out between $0 \mathrm{~Hz}$ and $128 \mathrm{~Hz}$ with the frequency resolution at $0.25 \mathrm{~Hz}$, the sampling frequency at $256 \mathrm{~Hz}$, time length of analysis at 4 seconds, and the window function as rectangle. Fig.7 shows the results of the analysis carried out for $0 \mathrm{~Hz}$ to $128 \mathrm{~Hz}$ with the frequency resolution at $0.0625 \mathrm{~Hz}$, the sampling frequency at 


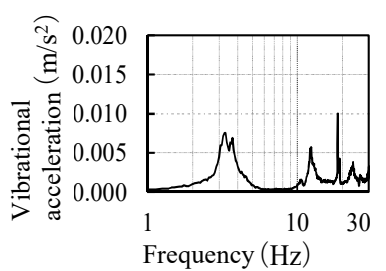

(a)TMD in Operation

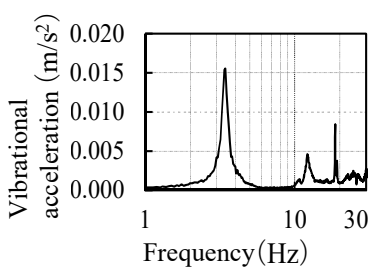

(b)TMD Not in operation

Fig.6 Frequency characteristics of main girder vibrational acceleration (at $1 / 2$ of span).
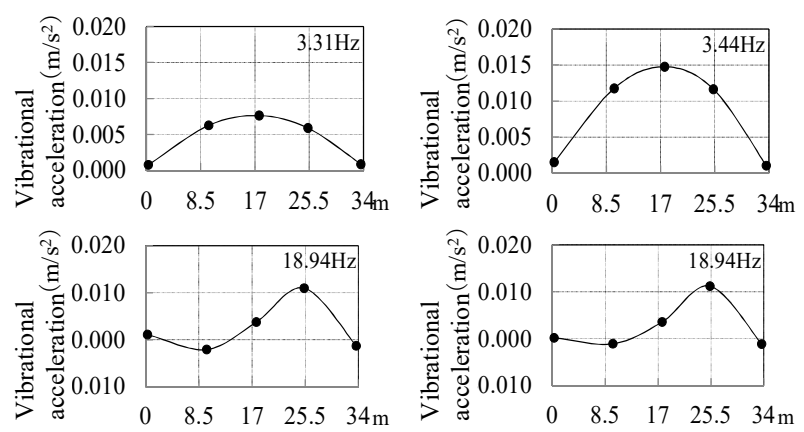

Fig.7 Vibration mode.

$256 \mathrm{~Hz}$, time length of analysis at 16 seconds, and the window function as rectangle. From the frequency characteristics, superiority is seen around $3.5 \mathrm{~Hz}$ and $19 \mathrm{~Hz}$. The vibration mode graphs indicate that they are each vibration primary mode and vibration secondary mode in the bridge axis direction. As for TMD's target eigenfrequency around $3.5 \mathrm{~Hz}$, we saw a reduction in the superiority of the vibration primary mode when TMD was in operation. The time history of waveforms for vibrational acceleration and lowfrequency noise level at $1 / 2$ point of span are shown in Fig.8. Although there are differences in the amplitude equality, the waveforms are almost the same and we can see that the emission of low-frequency noise is caused by the propagation of bridge-vibration into the atmosphere.

\section{OUTLINE OF GENERATION-TYPE TMD}

Fig.9 shows an analysis model of the single mass point generation-type TMD and bridge, created referring to a past study ${ }^{14)}$. This is a model of a single mass point tuned mass-type generation device, structured with springs, electromagnetic damping devices and a single mass added to an equivalent mass $\mathrm{M}$. The equivalent mass $M$ of bridge is supported by springs of spring constant $K$ and dampers of damping constant $C_{M}$. When harmonious outer force $F(t)=F_{0} \sin (\omega t)$ acts on mass M, displacement of mass $\mathrm{M}$ is $X(t)$ and displacement of Mass $m_{1}$ of generationtype TMD is $x_{1}(t) . m_{1}$ to $M$ mass ratio $\mu_{1}$ is $1 \%$. Since the characteristics of damping force $F_{e}(t)$, created by

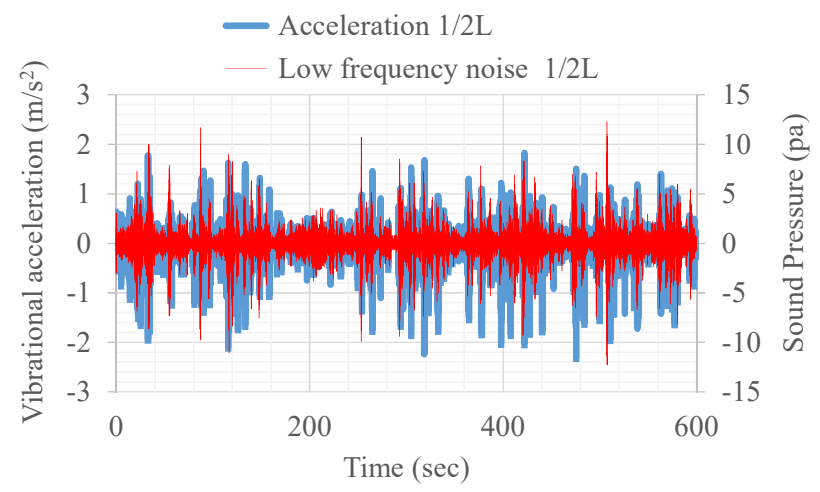

Fig.8 Time history waveform of vibrational acceleration and low-frequency noise pressure level.

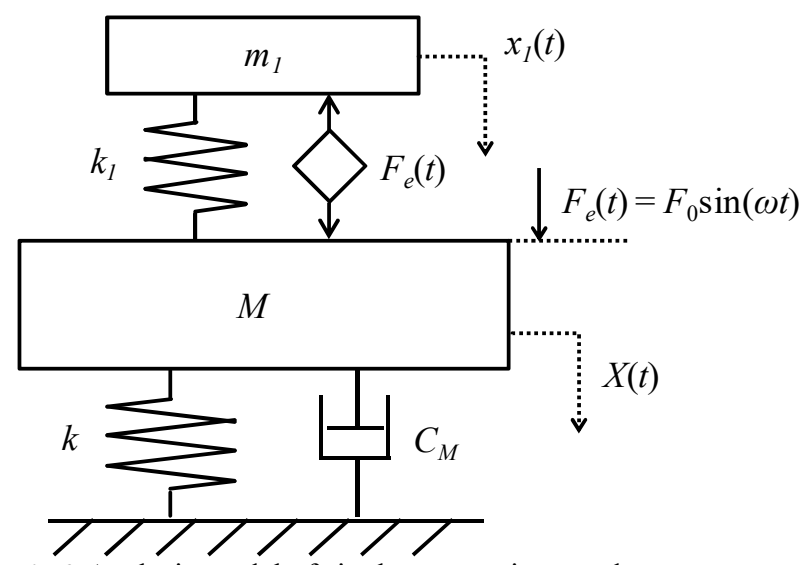

Fig.9 Analysis model of single mass point tuned mass type generation device and bridge.

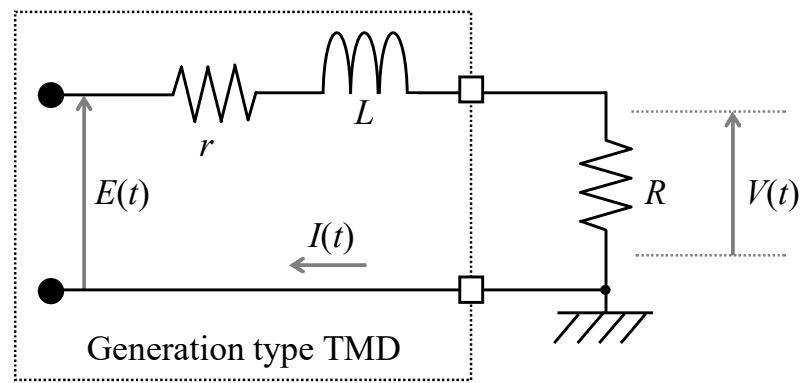

Fig.10 Electric circuit of generation-type TMD with electromagnetic damping device.

an electromagnetic damping device, change depending on the electric circuit connected to the internal structure of the electromagnetic damping device, we designed the electromagnetic device including the electric circuit.

\section{(1) Control by resistance $R$ of electric circuit}

We tested the electric circuit's internal resistance to verify if the electromagnetic damping device could control damping like the oil damper.

Fig.10 shows the equivalent circuit of the electromagnetic damping device and resistance $\mathrm{R}$, and the electric circuit of the generation-type TMD with internal resistance $r$ and self-inductance $L$.

The formula for the electromotive force $E(t)$ of the 
Table 2 System specifications.

\begin{tabular}{|c|c|c|}
\hline $\begin{array}{l}\text { Excitation } \\
\text { device }\end{array}$ & Transcend & MTS810 \\
\hline Data logger & KEYENCE & $\begin{array}{l}\text { NR-600 } \\
\text { HV04 unit }\end{array}$ \\
\hline $\begin{array}{l}\text { PC for data } \\
\text { storage }\end{array}$ & Panasonic & $\begin{array}{l}\text { Let's note } \\
\text { CF-SX3 }\end{array}$ \\
\hline $\begin{array}{l}\text { Distortion-type } \\
\text { load cell }\end{array}$ & $\begin{array}{l}\text { Tokyo Measuring } \\
\text { Instruments Lab. }\end{array}$ & TCLZ-5KNA \\
\hline $\begin{array}{l}\text { Dynamic } \\
\text { distortion meter }\end{array}$ & $\begin{array}{l}\text { Tokyo Measuring } \\
\text { Instruments Lab. }\end{array}$ & DPM-711B \\
\hline \multicolumn{3}{|c|}{ Settings } \\
\hline Sampling rate & $1000 \mathrm{~Hz}$ & \\
\hline AD resolution & 14 bit & \\
\hline Measurements & \multicolumn{2}{|c|}{ Measurement resolution } \\
\hline $\begin{array}{l}\text { Moving part } \\
\text { Displacement }[\mathrm{mm}]\end{array}$ & $6.10 \mu \mathrm{m}$ & \\
\hline $\begin{array}{l}\text { Load acting } \\
\text { on moving part }[\mathrm{N}]\end{array}$ & $15.3 \mathrm{mN}$ & \\
\hline $\begin{array}{l}\text { Generated } \\
\text { electromotive power }\end{array}$ & $1.22 \mathrm{mV}$ & \\
\hline
\end{tabular}

electromagnetic damping device can be expressed as follows, applying the change rate of magnetic field $d \phi / d t$ from Faraday's law of electromagnetic induction:

$$
E(t) \propto \frac{d \phi}{d t}
$$

The induced electromotive force can be expressed as follows, when magnetic field variance and velocity change $d x / d t$ of moving parts are proportional:

$$
E(t)=-k_{\text {emf }} \frac{d x}{d t}
$$

The value $k_{e m f}$ shows the ratio of electromotive force to velocity. When the inductive electromotive force coefficient is [V.s/m], the equation of the equivalent circuit of the electromagnetic damping device (Fig.10) and the damping force $\mathrm{Fe}(t)$ of the electromagnetic damping device can be expressed as follows.:

$$
\begin{gathered}
E(t)=(R+r) I(t)+L \frac{d I(t)}{d x} \\
F_{e}(t)=k_{\text {emf }} I(t)
\end{gathered}
$$

Generated power $W(t)$ and power loss $W_{\text {loss }}(t)$ are as follows:

$$
\begin{gathered}
W(t)=R I^{2}(t) \\
W_{\text {loss }}(t)=r I^{2}(t)
\end{gathered}
$$

Damping force caused by power generation of the electromagnetic damping device and equivalent damping coefficients $c_{e h}$ and $c_{e l}$ of damping by power

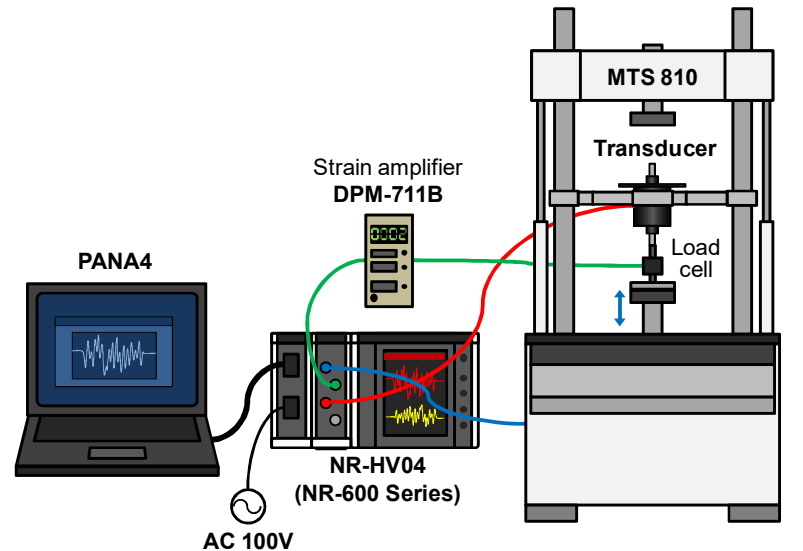

Fig.11 Electromagnetic characteristics test of electromagnetic damping device.

loss are expressed by the following formulas:

$$
\begin{gathered}
c_{e h}=\frac{k_{\text {emf }}^{2}}{r} \frac{R_{r}}{\left(1+R_{r}\right)^{2}} \\
c_{e l}=\frac{k_{e m f}^{2}}{r} \frac{1}{\left(1+R_{r}\right)^{2}}
\end{gathered}
$$

Here, $R_{r}=R / r$ is resistance ratio. Therefore, the equivalent damping coefficient $c_{e}$ can be represented by the sum of $c_{e h}$ and $c_{e}$.

$$
c_{e}=c_{e h}+c_{e l}
$$

From the above, it is clear that damping force $\mathrm{Fe}(t)$ of the electromagnetic damping device and generated power $W(t)$ contribute to the equivalent damping coefficient $c_{e h}$ derived from power generation of the electromagnetic damping device. This shows that the damping effect (vibration control) and power generation of the generation-type TMD may be controlled by changing resistance $R$ within the electromagnetic damping device.

\section{(2) Verification test for power generation and mechanical characteristics}

Laboratory tests using a vibration table were carried out to determine the power generation and mechanical characteristics of the electromagnetic damping device, which will be used for testing on an actual bridge. Fig.11 is a sketch of the test system, and the specifications of the test system are shown in Table 2. We used MTS810 as the excitation device. As shown in Fig.12, the electromagnetic damping device is fastened to the MTS810 frame by a single-purpose jig tool, and the shaft is fixed to the vibration table with the distortion-type load cell placed in between. The vibration table is controlled by the MTS 810 controller, and the displacement [mm] of the vibration table output from MTS810, the load [N] output from distortion-type load cell, and the electromotive force $[\mathrm{V}]$ output from the electromagnetic damping device were measured using the NR-HV04 unit of the 


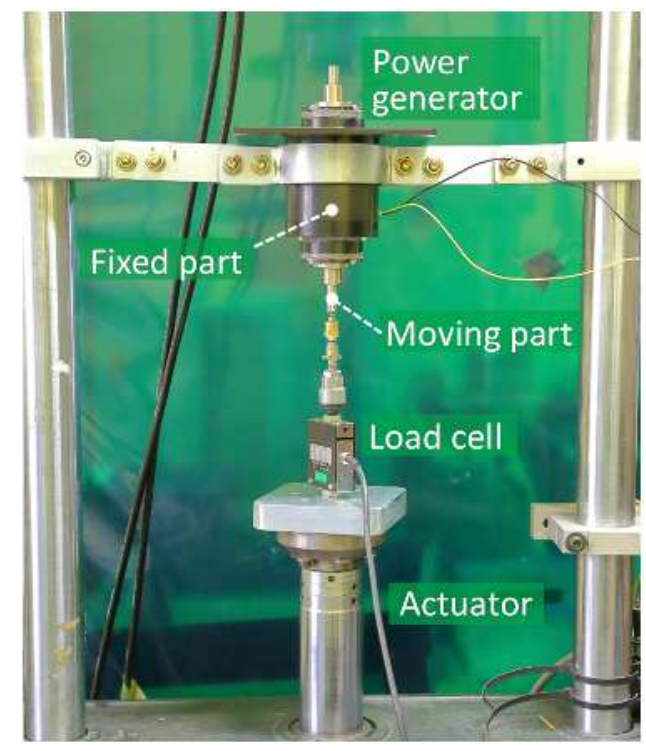

Fig.12 Electromagnetic damping device installed in excitation device.

NR-600 series. Table 3 shows the settings of the logger.

To find the relationship between the electromotive force coefficient and displacement calculated in the experiment, the electromotive force was measured after applying constant velocity excitation, created by a triangle waveform, to the moving part. Fig.13 shows, from the top, the displacement time history of the moving part of the electromagnetic damping device, the time history of the velocity derived by differentiating the displacement of the moving part with the frequency domain, and the time history of power generation voltage of the electromagnetic damping device. The excitation velocity was $5 \mathrm{~mm} / \mathrm{s}$, and the vibration width was $\pm 20 \mathrm{~mm}$.

Fig.14 shows the generation voltage waveform derived from the experiment and the electromotive force coefficient $k_{\text {emf }}$ of the electromagnetic damping device calculated from the moving-part velocity. The vertical axis in Fig.14 is electromotive force coefficient $k_{e m f}$ and the horizontal axis shows the position of the moving part when the upside of the electromagnetic damping device is positive. The red line represents electromotive forcer coefficient when the moving part moves downward. The blue line represents electromotive force coefficient when the moving part moves upward. The small divergence between the red and blue lines is likely caused by the hysteresis characteristic of the electromagnetic damping device. The influence of the hysteresis characteristics is small in the single-digit $\mathrm{Hz}$ low-frequency band, and therefore, it was ignored in the numerical analysis of this study. From the above, we used the relationship between electromotive force coefficient $k_{e m f}$ and moving part position $x$ [mm] obtained by the test, shown in Fig.14.
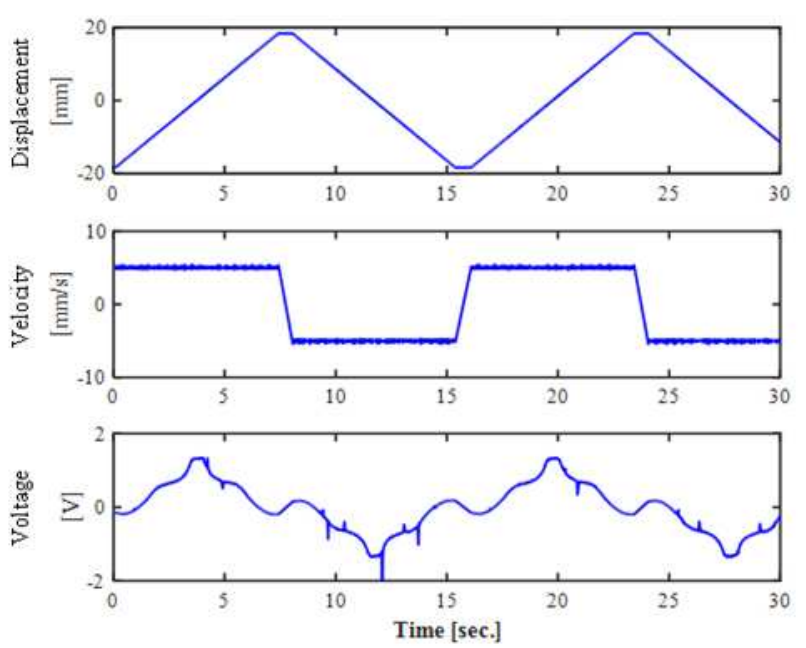

Fig.13 Time history of moving part displacement, time history of moving part speed, and time history waveform of generated electromotive force.

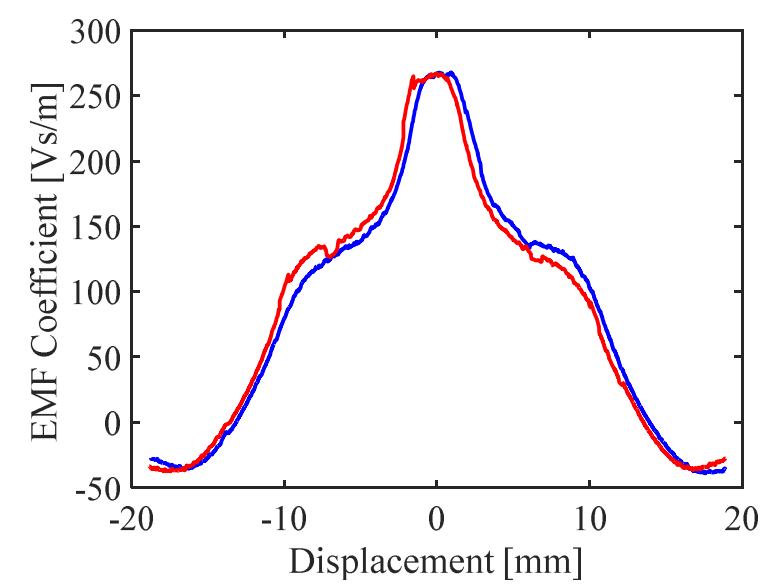

Fig.14 Relation between electromotive force coefficient of electromagnetic damping device and position of moving part.

Fig.15 shows the relationship, obtained by the test, between the reaction force that the moving part receives when it is activated and the position of the moving part. The vertical axis in Fig.15 represents the reaction force received by the moving part (upward positive), and the horizontal axis represents the position of the moving part when the upside of the electromagnetic damping device is positive. The inside of the trajectory made by the reaction force and moving-part displacement is the energy loss caused by dynamic friction. The upper trajectory is for when the moving part moves up and down. The lower trajectory is for when the moving part moves downward. Since a half of the difference between the upper trajectory and lower trajectory is considered dynamic friction force, we calculated the dynamic friction force and showed its relationship to the position of the moving part in Fig.16. As shown in Fig.16, the peak frictional resistance of the moving part is observed around the neutral position of the moving part, and the frictional resistance lowers as the moving part 


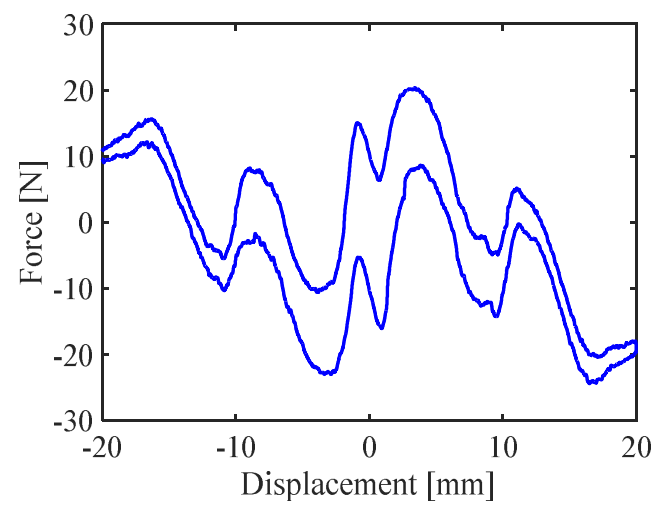

Fig.15 Displacement time history of load acting on moving part of electromagnetic damping device.

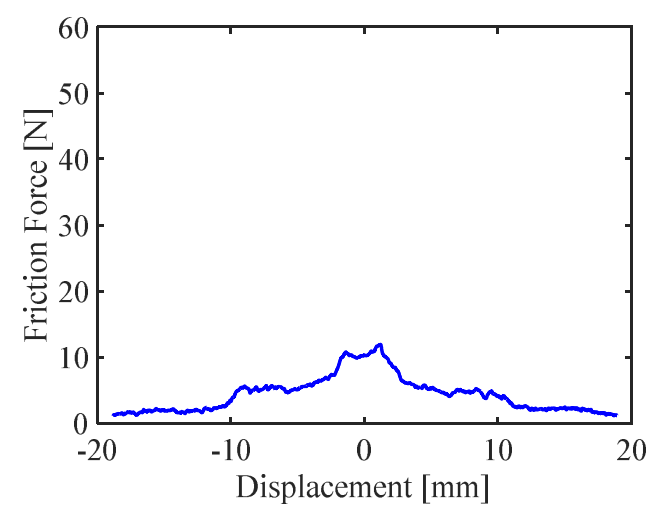

Fig.16 Relation between dynamic friction force and position of moving part of electromagnetic damping device.

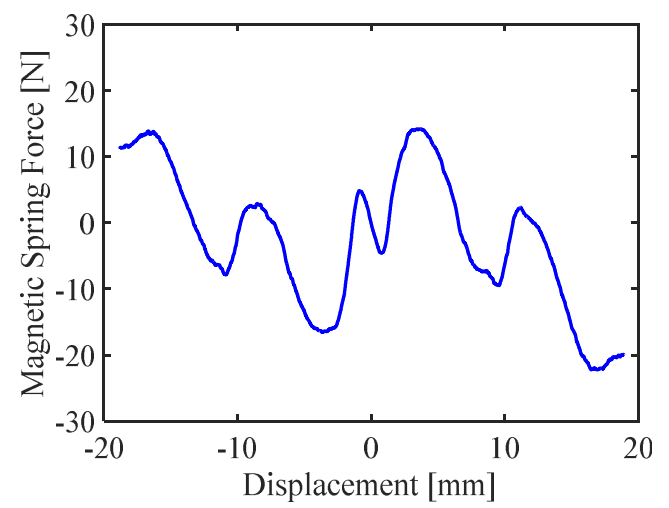

Fig.17 Relation between magnetic spring and position of moving part of electromagnetic damping device.

moves away from its neutral position. It is thought that gravitation in the centrifugal direction between the magnet of the moving part and the yoke of the fixed part is strongest near the neutral position. This suggests that there is increasing friction generated at the bearing. The mean dynamic friction is about $6 \mathrm{~N}$ within the $\pm 10 \mathrm{~mm}$ range of the vibration, estimated for most vibration-powered generation. The reaction force generated by the magnetic spring may be calculated by subtracting the influence of dynamic friction (Fig.16) from the relation between reaction force received by the moving part and the position of the moving part (Fig.15). Fig.17 shows the relationship between the reaction force of magnetic spring and the position of the moving part. When the moving part is within a $\pm 2 \mathrm{~mm}$ range, the magnetic spring exhibits a positive spring behavior, and within a $\pm 2 \mathrm{~mm}$ to \pm 8 $\mathrm{mm}$ range, the magnetic spring exhibits a negative spring behavior. This indicates that the absolute value of the magnetic spring's maximum reaction force is held small by having complex characteristics that alternate between positive and negative spring behavior. The results show that the magnetic spring's influence on the tuning of the vibration frequency of the generation-type TMD becomes relatively small.

\section{STUDY BY NUMERICAL SIMULATION}

We studied the resistance of the electric circuit to determine the vibration control and power generation characteristics of the electromagnetic damping device installed on the TMD of the bridge used in the test. To verify how damping effect and amount of power generation is controlled, the following three types of electromagnetic damping devices were examined to calculate the ideal electric resistance value:

(a) A type focusing on reducing peak vibration that keeps the peak of the frequency spectrum of the vibrational acceleration to minimum.

(b) A type focusing on energy absorption that maximizes the absorbed energy using attenuation of the electromagnetic damping device.

(c) A type focusing on power generation that generates maximum energy.

\section{(1) Outline of numerical simulation model}

Fig.8 shows the numerical simulation model. The target frequency of the bridge was set as $f=3.4 \mathrm{~Hz}$, considering primary vibration mode characteristics of the test bridge. The effective mass of the bridge's target vibration mode is $M=205000 \mathrm{~kg}$. The mode damping ratio of the bridge tends to depend on the vibration stroke. However, the damping ratio shall be $\zeta=3.0 \%$, which was obtained by formula (8) applying the free damping waveform representing vibrations at about 50 to 100 gal deemed to be typical vibrations caused by an average traffic load on actual bridges. The mass of a $1500 \mathrm{~kg}$ generation-type TMD is $m_{1}=1560 \mathrm{~kg}$, considering the mass of the adjusting mass; the natural frequency is $f_{1}=3.45 \mathrm{~Hz}$.

A numerical simulation was carried out to calculate the mechanical damping ratio of the spring mass using $\zeta_{1}=2.0 \%$, which was obtained from formula (8) using the free damping vibration waveform. Four electromagnetic damping devices, the maximum number possible, were installed. We used nonlinear characteristics obtained from the experiment for both 
the electromotive force coefficient $k_{\text {emf }}$ and magnetic spring characteristic $F_{g}$. (Fig.14, Fig.17). The internal resistance of the electromagnetic damping device is $r=10.3 \Omega$. The frictional resistance generated in the electromagnetic damping device or friction caused by imperfect alignment of axis, when an electromagnetic damping device is installed on TMD, affect the damping characteristics of the generation-type TMD. Though it is considered that these also influence tuning of the electric resistance, it is difficult to measure the entire friction resistance $\sigma_{g}$ of the generation-type

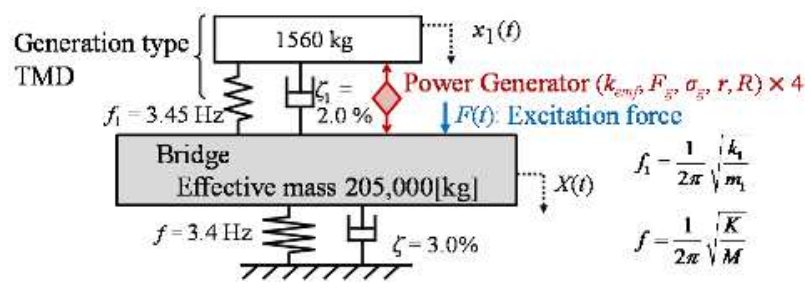

Fig.18 Simulation model of bridge with generation-type TMD.

Table 4 Numerical simulation parameters.

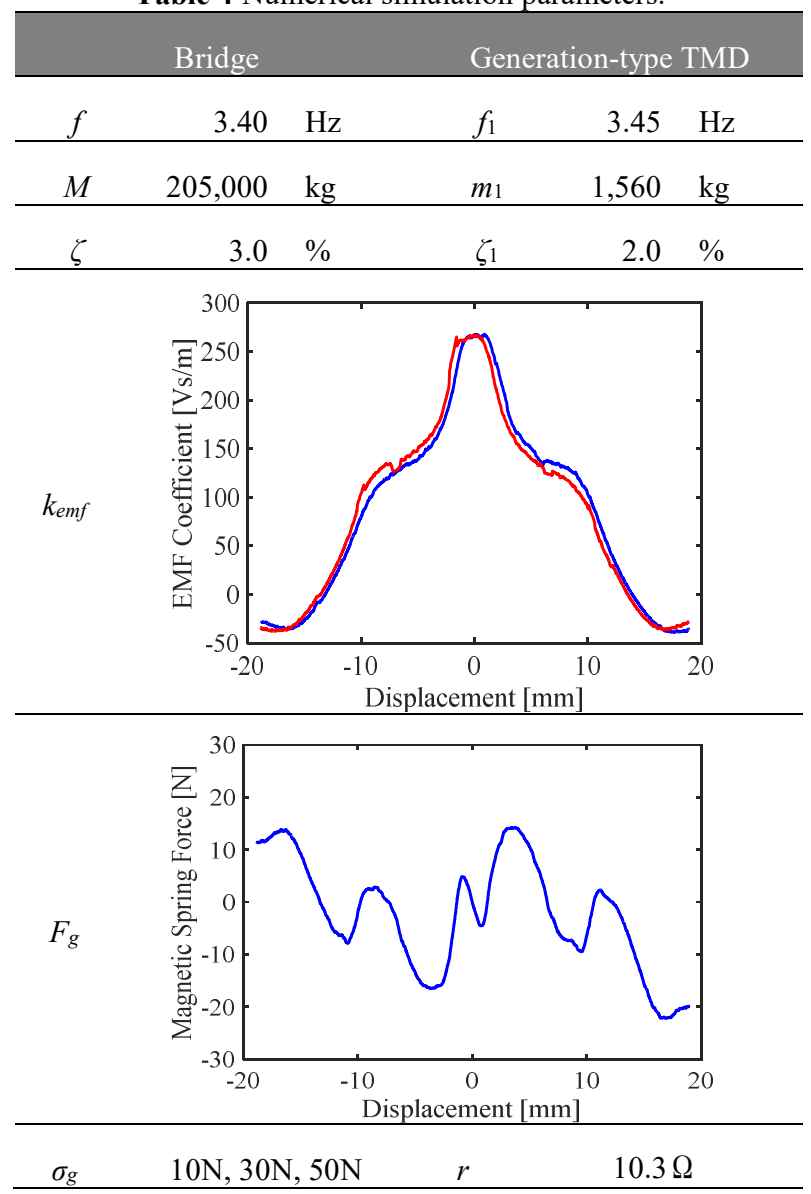

TMD in an experiment. Therefore, in this study, we set three conceivable patterns of frictional resistance $\sigma_{g}$ of the entire generation-type TMD and examined which resistance was suitable to the purposes of these patterns. The three frictional resistances $\left(\sigma_{g}\right)$ studied are $10 \mathrm{~N}, 30 \mathrm{~N}$ and $50 \mathrm{~N}$.

$$
\zeta=\frac{C_{M}}{2 \sqrt{M K}}, \zeta_{1}=\frac{C_{1}}{2 \sqrt{m_{1} k_{1}}}
$$

Bridge damping energy $=\int C_{M} \dot{X}^{2} d t$

Energy absorption $=$

$$
\int\left\{\sigma_{g}\left|\dot{x}_{1}-\dot{X}\right|+\left(c_{1}+4 \cdot c_{e}\right)\left(\dot{x}_{1}-\dot{X}\right)^{2}\right\} d t
$$

Power generation $=$

$$
R(r+R)^{-1} \int 4 \cdot c_{e}\left(\dot{x}_{1}-\dot{X}\right)^{2} d t
$$

Generation damping coefficient ce, which represents attenuation of power generation by the electromagnetic damping device, is given in the following formula:

$$
c_{e}(x)=\frac{k_{e m f}^{2}(x)}{r+R}
$$

All necessary parameters for numerical simulations are shown in Table 4.

First, to analyze the influence of frictional resistance and resistance value $\mathrm{R}$ of electric circuit to bridge-vibration, an equivalent excitation power caused by vehicle traffic is applied to the model of bridge with generation-type TMD, shown in Fig.18. Equivalent excitation power was calculated using the method proposed by Taguchi et al. ${ }^{15}$, derived from measured vibration acceleration data. In this analysis, we used four hours' worth of equivalent excitation force indicated by the red frame in Fig.19. The power spectrum density of bridge acceleration for that time is shown in Fig.20.

Black lines (original) represent regular TMD in operation. Fig.20 shows three simulation results for each friction resistance and how the spectrum varies when electric resistances are changed in each case. The black line shows the power spectrum density derived from acceleration data actually measured at the test bridge with conventional TMDs using viscous dampers. We see that attenuation by power generation of electromagnetic damping device increases as

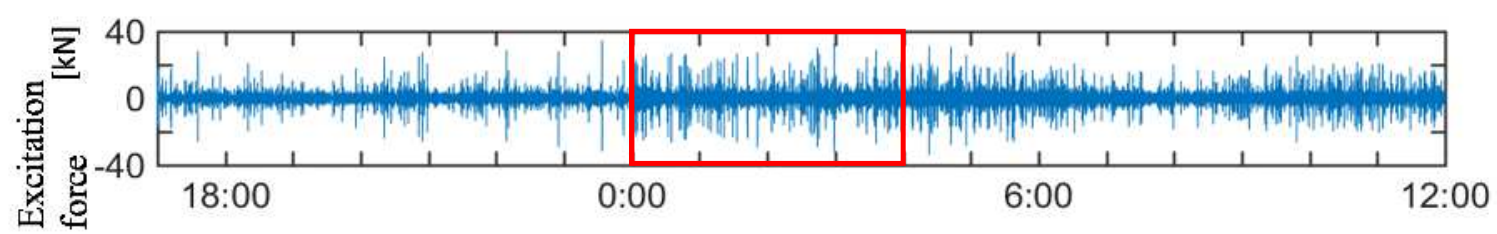

Fig.19 Excitation force by traffic load (19 hours)(Red frame indicates excitation force used for numerical simulation in Fig.20). 
electric resistance grows. When the total friction damping force of generation-type TMD is $10 \mathrm{~N}$, the maximum value of spectrum turns minimal by setting electric resistance $R$ at $70 \Omega$. On the other hand, when the total friction damping force is $30 \mathrm{~N}$, the maximum value of spectrum turns minimal at around $120 \Omega$. When the total friction damping force is $50 \mathrm{~N}$, attenuation by friction becomes dominant and diminishes the damping effect by power generation.

\section{(1) Study on resistance value settings for specific purposes}

Next, to analyze influences of electric circuit resistance on vibration of bridge and power generation, we studied the relationships between resistance and peak vibration, energy absorption, and power generation, which were the design targets of the three types of electromagnetic damping devices. We referred to past documents ${ }^{12), 14)}$ for the calculations, shown in formulas (9) to (11). For the calculation, excitation force (19 hrs.) of traffic load was applied to the simulation model of the bridge installed with the generation-type TMD (Fig.18). Also, (a) the maximum peak value of power spectrum density of bridge acceleration when electric resistance $R$ was changed between $0 \Omega$ and $1000 \Omega$, (b) vibration energy absorbed by generation-type TMD damping device, and friction damping using formula (9), and (c) power generation using formula (10) were each calculated, applying the numerical analysis results. The results are shown in Fig.21 to Fig.23.

Fig.21 is for when frictional resistance is $10 \mathrm{~N}$, Fig.22 is for 30N, and Fig.23 is for 50N.Focusing on controlling the vibration of bridge when the frictional resistance is $10 \mathrm{~N}$, the maximum value of power spectrum density function of bridge acceleration becomes minimum when electric resistance is $80 \Omega$. And power generation is maximum when electric resistance is $70 \Omega$. From the case studies of the actual bridge test, we found that the optimum electric resistance for vibration control and that for power generation are close when the friction resistance is small (equivalent to $10 \mathrm{~N}$ ). On the other hand, focusing on energy absorption of the power generation-type TMD, electric resistance is maximum at around $200 \Omega$. We see that the absorbable amount of energy barely changes at electric resistance of $200 \Omega$ or more.

When focusing on controlling the vibration of bridge when the friction resistance is $30 \mathrm{~N}$, electric resistance is $140 \Omega$ when the maximum value of power spectrum density function of bridge acceleration becomes minimum. And power generation becomes maximum at electric resistance $70 \Omega$. The test results show different optimum values of electric resistance for controlling vibration and for power generation when friction resistance is equivalent to $30 \mathrm{~N}$. On the

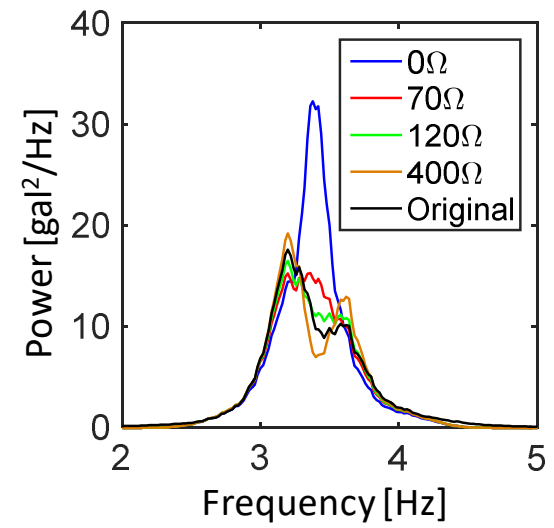

(a) Total friction resistance of generation-type TMD is $10 \mathrm{~N}$

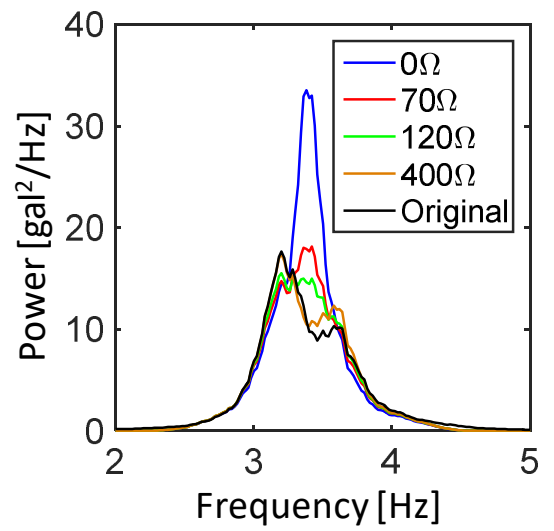

(b) Total friction resistance of generation-type TMD is $30 \mathrm{~N}$

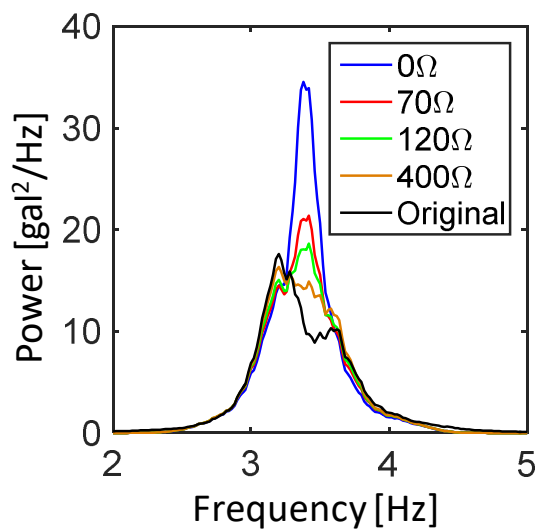

(c) Total friction resistance of generation-type TMD is $50 \mathrm{~N}$

Fig.20 Spectrum density function and resistance setting when generation-type TMD is installed on bridge.

other hand, focusing on energy absorption of the power generation-type TMD, electric resistance becomes maximum near $400 \Omega$. And the amount of energy absorption barely changes at electric resistance $400 \Omega$ or more. When focusing on controlling vibration of the bridge when the friction resistance is 50 $\mathrm{N}$, electric resistance is around $500 \Omega$ when the maximum value of the power spectrum density function of bridge acceleration turns minimum. We see that the maximum value of the power spectrum function 

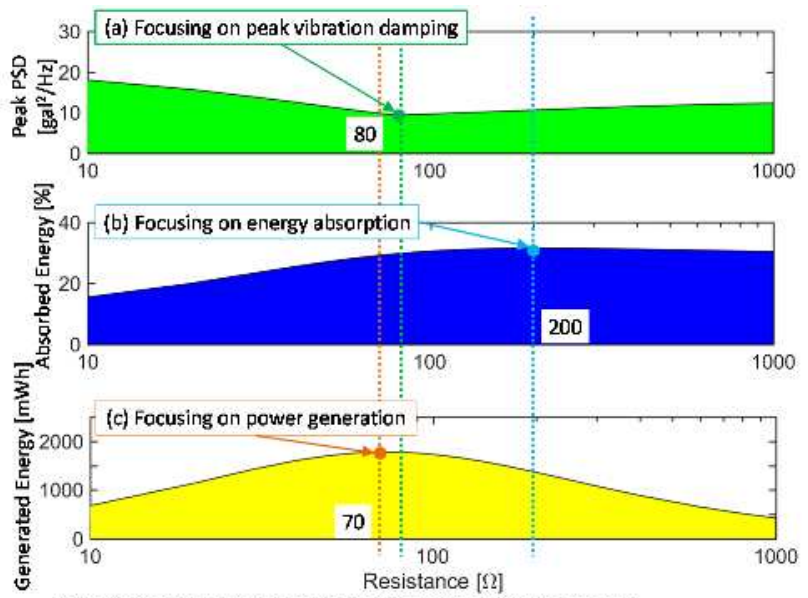

*1 Indicates the percentage of absorbed bridge vibration energy

Fig.21 Maximum peak value of power spectrum density function of bridge acceleration, results of energy absorption and power generation (Total friction resistance 10N).
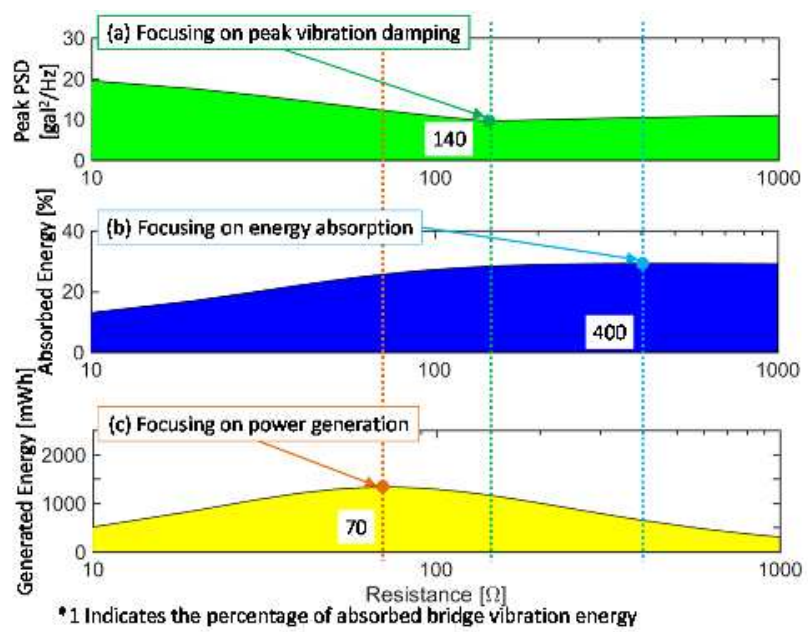

Fig.22 Maximum peak value of power spectrum density function of bridge acceleration, results of energy absorption and power generation (Total friction resistance $30 \mathrm{~N}$ ).
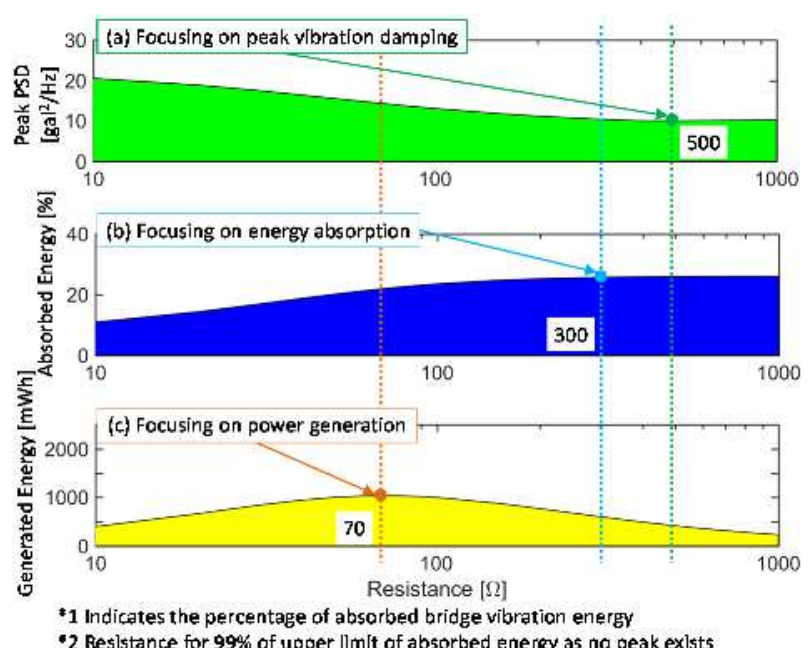

Fig.23 Maximum peak value of power spectrum density function of bridge acceleration, results of energy absorption and power generation (Total friction resistance $50 \mathrm{~N}$ ). barely changes at electric resistance of $500 \Omega$ or more. On the other hand, power generation energy reaches its peak at electric resistance $70 \Omega$. An optimum electric resistance that maximizes energy absorption of generation-type TMD does not exist between $0 \Omega$ and $1000 \Omega$, and energy absorption barely changes at $300 \Omega$ or more. This means that frictional resistance is large and dominant, and it is likely that the influence of tuning by electric resistance on power generation-type TMD is relatively small.

The simulation results of each friction resistance are shown in Table 5. When the purpose is (a) peak vibration damping to control vibration, peak vibration can be minimized by setting electric resistance high when the frictional force of power generationtype TMD is high. When the purpose is (b) energy absorption to control vibration, energy absorption can be maximized by setting the electric resistance high if the frictional force of the generation-type TMD is high. But when the friction is around $50 \mathrm{~N}$ or less, the influence of friction is dominant and energy absorption does not change when resistance is $400 \Omega$ or more. On the other hand, if the purpose is (c) power generation, the most suitable electric resistance does not depend on the frictional force of the $1500 \mathrm{~kg}$ power generation-type TMD and is $70 \Omega$.

In this study, to minimize the tests affecting surrounding areas, we used just two electromagnetic damping devices and the remaining two were oil dampers. Although electromagnetic damping devices $\mathrm{A}$ and $\mathrm{B}$ used in the experiment have different frictional forces, $6 \mathrm{~N}$ and $20 \mathrm{~N}$, near the center, we used these two since the frictional forces were relatively small. Therefore, the total friction of the $1500 \mathrm{~kg}$ power generation-type TMD equipped with electromagnetic damping devices $\mathrm{A}$ and $\mathrm{B}$ is considered to be around $30 \mathrm{~N}$, considering misalignment in assembling. The relationships between the most suitable electric resistance $R_{4}^{*}$, based on the numerical simulation result using four electromagnetic damping devices and the most suitable electric resistance $R_{2}^{*}$ to get equivalent power-generation damping when two electromagnetic damping devices are used can be derived by formula 13 as follows.:

$$
R_{2}^{*}=\left(R_{4}^{*}-r\right) / 2
$$

The most suitable resistances were set for each case as follows, considering total friction resistance $30 \mathrm{~N}$ when two electromagnetic damping devices are installed:

(a) Aiming to reduce peak vibration level : $100 \Omega$

(b) Aiming for energy absorption : $200 \Omega$

(c) Aiming for power generation: $100 \Omega$ 
Table 5 Summary of generation-type TMD power generation, maximum value of power spectrum density function of bridge acceleration and energy absorption.

\begin{tabular}{ccccccccccc} 
& \multicolumn{3}{c}{ (a) Focusing on peak } & \multicolumn{2}{c}{ (b) Focusing on } \\
vibration damping & \multicolumn{5}{c}{$\begin{array}{c}\text { (c) Focusing on } \\
\text { power generation }\end{array}$} \\
Friction of generation-type TMD & $10 \mathrm{~N}$ & $30 \mathrm{~N}$ & $50 \mathrm{~N}$ & $10 \mathrm{~N}$ & $30 \mathrm{~N}$ & $50 \mathrm{~N}$ & \multicolumn{1}{c}{$10 \mathrm{~N}$} & $30 \mathrm{~N}$ & $50 \mathrm{~N}$ \\
\hline \hline Optimum electric resistance & $80 \Omega$ & $140 \Omega$ & $500 \Omega$ & $200 \Omega$ & $400 \Omega$ & $300 \Omega$ & $70 \Omega$ & $70 \Omega$ & $70 \Omega$ \\
\hline Peak vibration level $\left[\mathrm{gal}^{2} / \mathrm{Hz}\right]$ & 9.42 & 9.65 & 10.04 & 10.63 & 10.44 & 10.46 & 9.89 & 12.24 & 14.36 \\
\hline Energy absorption $[\%]$ & 29.77 & 28.24 & 25.95 & 31.60 & 29.23 & 25.71 & 29.14 & 25.60 & 22.02 \\
\hline Power generation $[\mathrm{mWh}]$ & 1,775 & 1,172 & 415 & 1,361 & 645 & 602 & 1,778 & 1,330 & 1,036 \\
\hline
\end{tabular}

\section{EXPERIMENT ON AN ACTUAL EXPRESSWAY BRIDGE IN SERVICE}

\section{(1) Outline of experiment}

Experiments were carried out to verify the usability of the numerical simulation design for expressway bridges in service. The bridge used in the test stood near a residential area and was causing environmental problems. So, to minimize environmental problems caused by the tests, of the three TMDs installed, we replaced one TMD at the center in the perpendicular direction to the bridge axis with a power generation-type TMD. The tested TMD is shown in Fig.24. The electromagnetic damping devices used to replace oil dampers were the two devices, A and B, adopted for designing. They were diagonally placed as shown in Fig.25. We used a variable resistor to make it easier to set the three electric resistances derived from numerical simulations. To determine the damping amount of the generation-type TMD, we installed a vibrational accelerometer in the center of the upper side of the generation-type TMD mass. And a displacement gauge was installed to measure the relative displacement between power generation TMD mass and the cross beam of the installation rack. The measured damping amount is shown in Fig.26. To determine the damping effects and reduction of low-frequency noise, we installed vibrational acceleration meters and low-frequency level meters as shown in Fig.5.

\section{(2) Test results and examination of the results}

In the experiment, we tested three electric resistances, each for a week. We measured the vibrational accelerations and low-frequency noise of bridge and TMD, and the amount of power generation.

Based on the measurements, we calculated the damping damping device (right) amount. For bridgevibration damping and low-frequency noise reduction, we compared the oil damper and the electromagnetic damping device and analyzed the usefulness of the numerical simulation results.

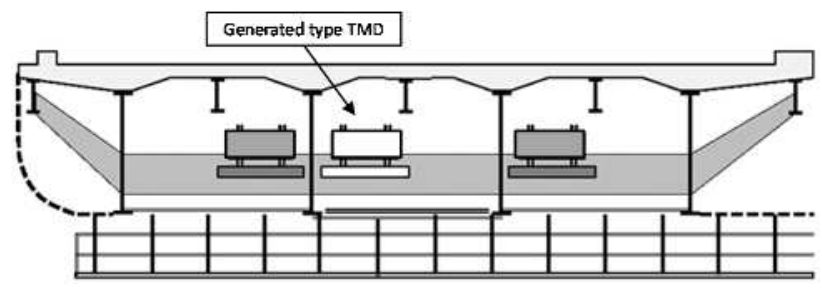

Fig.24 Tested TMD.
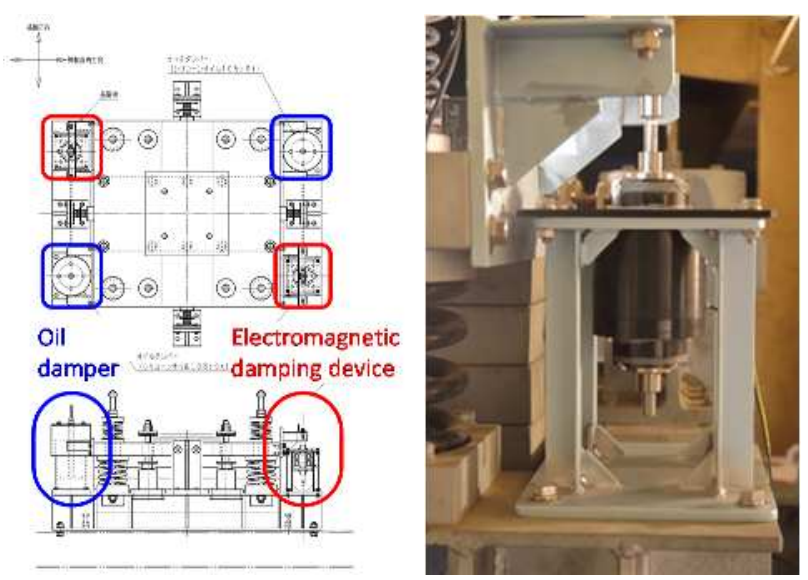

Fig.25 Generation-type TMD (left) Electromagnetic.

\section{a) Damping amount}

For the free vibration waveform to confirm damping ratio $\zeta_{A}$ of vibrational acceleration of the generation-type TMD installed on the test bridge, we used the waveform that was shaped when the vibration mass of the TMD settled after being vibrated by traffic disturbance via the bridge. For the measurements, we used a vibrational acceleration meter installed on the generation-type TMD mass, as shown in Fig.26. For the analysis, we extracted stable points of the free vibration start acceleration, using data of the vibrational acceleration meter installed on the vibration mass, and checked the free vibration waveform using formula (14).

In this measurement, the free vibration start acceleration of the vibration mass was also set at $200 \mathrm{~cm} / \mathrm{s}^{2}$. As for calculating the damping ratio $\zeta_{A}$, we extracted values of 4 to 5 wave length from the free vibration waveform of the relative displacement, which were measured simultaneously with acceleration, after the start of analysis. We calculated each damping ratio 


$$
\zeta_{A}=\sqrt{\frac{2 \pi}{\left.\ln \left(\frac{x_{n}}{x_{n+1}}\right)\right\}^{2}+1}}
$$

from the three waveforms and evaluated the average as damping ratio $\zeta_{A}$. Calculation examples of damping ratio $\zeta_{A}$ are shown in Fig.27 and Table 6.

\section{b) Damping effect}

To verify bridge-vibration damping and low-frequency noise reduction effects of power generationtype TMD, we measured the vibrational acceleration and low-frequency noise to determine the vibration characteristics of the bridge by operating the TMD's oil damper part under the follow conditions: (a) using oil dampers, setting electric resistance at (b) 30 $\Omega$, (c) $100 \Omega$ and (d) $200 \Omega$. Sampling points are at $1 / 2$ span as shown in Fig.5. The vibrational acceleration meter was installed on the flange under the reinforcing vertical beam, and the low-frequency noise level meter was placed on the backside acoustical board. Measurements were taken during the test periods and 10 minutes of each test period when there was heavy large-vehicle traffic.

Frequency characteristics of the measured vibrational acceleration are shown in Fig.28. When looking at TMD's target eigenfrequency around $3.5 \mathrm{~Hz}$, although no damping effect is observed at $30 \Omega$ and superiority in the power spectrum value is seen, superiority in the power spectrum value is diminished by the damping effect of the oil damper, and similar damping effects can be seen for both $100 \Omega$ and $200 \Omega$. But since the measurements were taken under different conditions, such as time and day and external forces owing to traffic conditions, the power spectrum values could not be compared and evaluated. Therefore, we calculated the total power spectrum values for each frequency between $10 \mathrm{~Hz}$ and $30 \mathrm{~Hz}$, which were out of the target natural frequency range of TMD and compared them with large-vehicle traffic during the test period (Table 7). Their correlations are shown in Fig.29. Since the total power spectrum value and large-vehicle traffic volume show a high correlation, we standardized traffic conditions by multiplying the ratio with the average large-vehicle traffic volume. We likewise calculated the power spectrum value from $3.25 \mathrm{~Hz}$ to $3.5 \mathrm{~Hz}$, which were around the target eigenfrequency of TMD, and using the ratio to the total power spectrum between $10 \mathrm{~Hz}$ and $30 \mathrm{~Hz}$,evaluated the damping capacity of the power generation-type TMD. The results are shown in Table 8, Fig.30, and Fig.31.

When focusing on power generation, the damping

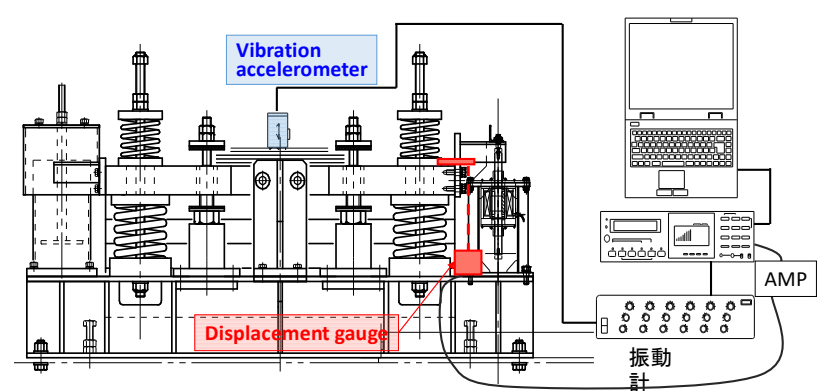

Fig.26 Measuring damping amount.

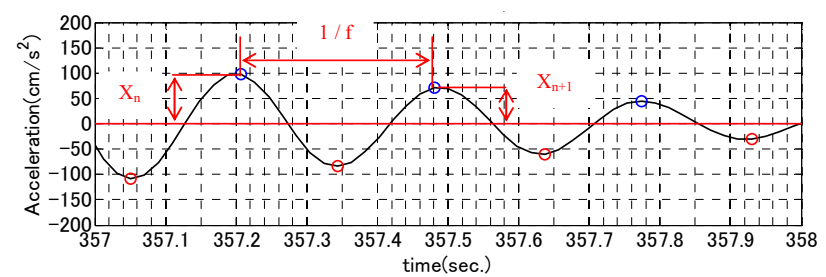

Fig.27 Calculation example of damping Ratio $\zeta_{A}$ using free vibration waveform.

Table 6 Calculation results of damping ratio $\zeta_{A}$.

\begin{tabular}{cccc}
\hline No. of tests & (1) $30 \Omega$ & (2) $100 \Omega$ & (3) $200 \Omega$ \\
\hline 1 & $6.87 \%$ & $5.27 \%$ & $5.04 \%$ \\
\hline 2 & $6.58 \%$ & $5.30 \%$ & $4.88 \%$ \\
\hline 3 & $6.60 \%$ & $5.96 \%$ & $4.83 \%$ \\
\hline Average & $6.68 \%$ & $5.51 \%$ & $4.92 \%$ \\
\hline
\end{tabular}

effect is small at $30 \Omega$, though the power spectrum ratio between $10 \mathrm{~Hz}$ and $30 \mathrm{~Hz}$ is large. The damping effect at $100 \Omega$, aiming at reducing peak vibration, is at the same level as the damping effect of oil dampers.

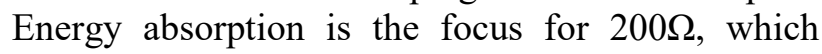
shows damping effect but is lower than that of oil dampers and at $100 \Omega$.

We also analyzed low-frequency noise, in the same way that we did for vibrational acceleration. The measured frequency characteristics of vibrational acceleration are shown in Fig.32. We calculated the total power spectrum values for between $10 \mathrm{~Hz}$ and $30 \mathrm{~Hz}$ and compared them with large-vehicle traffic volumes. The results are shown in Table 9, and the correlation is shown in Fig.33. After calculating the power spectrum values for between $3.25 \mathrm{~Hz}$ and $3.5 \mathrm{~Hz}$ in the same way, we evaluated the damping effects of power generation-type TMD using the ratio to the total power spectrum value of between $10 \mathrm{~Hz}$ and $30 \mathrm{~Hz}$. The calculated results are shown in Table 10, Fig.34, and Fig.35.

Though the correlation between the total value of power spectrum and large-vehicle traffic volume is not as high as that with vibrational acceleration, the time history waveforms of vibrational acceleration and low-frequency noise appear almost the same, as shown in Fig.8. Since bridge-vibration propagates into the atmosphere and emits low-frequency noise, the same tendency as vibration acceleration can be 


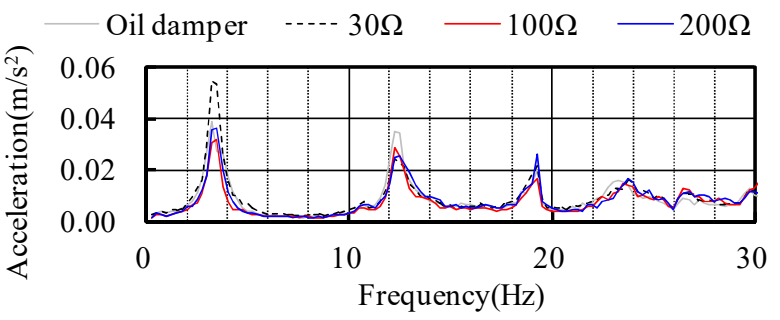

Fig.28 Frequency characteristics of vibrational acceleration.

Table 7 Total power spectrum value between $10 \mathrm{~Hz}$ and $30 \mathrm{~Hz}$ and large-vehicle traffic.

\begin{tabular}{ccccc}
\hline & $\begin{array}{c}\text { Oil } \\
\text { damper }\end{array}$ & $30 \Omega$ & $100 \Omega$ & $200 \Omega$ \\
\hline $\begin{array}{c}\text { Power Spectrum } \\
\left(\mathrm{m} / \mathrm{s}^{2}\right)\end{array}$ & 0.754 & 0.761 & 0.685 & 0.750 \\
\hline $\begin{array}{c}\text { Heavy Vehicle } \\
(\text { cars })\end{array}$ & 278 & 288 & 247 & 282 \\
\hline
\end{tabular}

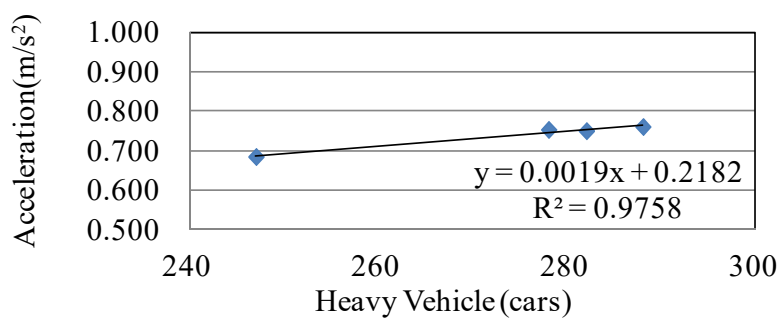

Fig.29 Correlation of total power spectrum between $10 \mathrm{~Hz}$ and $30 \mathrm{~Hz}$ and large-vehicle traffic.

Table 8 Total power spectrum ratio between 3.25 and $3.5 \mathrm{~Hz}$ to $10 \mathrm{~Hz}$ and $30 \mathrm{~Hz}$.

\begin{tabular}{lcccc}
\hline & $\begin{array}{c}\text { Oil } \\
\text { damper }\end{array}$ & $30 \Omega$ & $100 \Omega$ & $200 \Omega$ \\
\hline (1) $3.25-3.5 \mathrm{~Hz}$ & 0.066 & 0.108 & 0.062 & 0.072 \\
\hline$(2) 10-30 \mathrm{~Hz}$ & 0.754 & 0.761 & 0.685 & 0.750 \\
\hline$(3)$ Ratio & 1.016 & 1.052 & 0.902 & 1.030 \\
\hline$(1) /(2) \times(3)$ & 0.089 & 0.149 & 0.082 & 0.099 \\
\hline
\end{tabular}

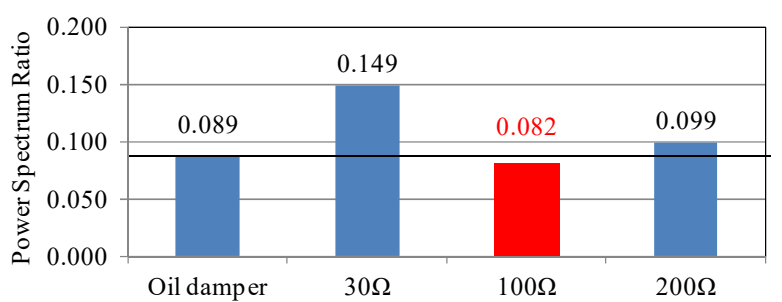

Fig.30 Power spectrum ratio around target eigenfrequency of TMD.

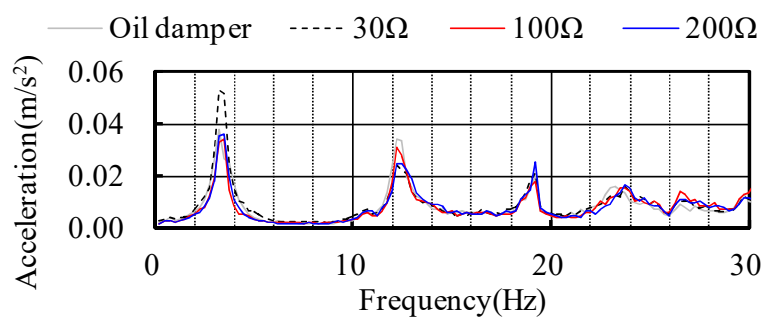

Fig.31 Frequency characteristic of vibrational acceleration standardized by large-vehicle traffic volume.

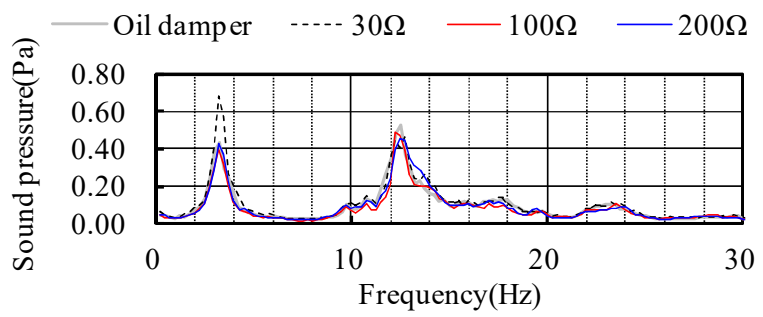

Fig.32 Frequency characteristics of low-frequency noise.

Table 9 Total power spectrum between $10 \mathrm{~Hz}$ and $30 \mathrm{~Hz}$ to largevehicle traffic volume.

\begin{tabular}{ccccc}
\hline & $\begin{array}{c}\text { Oil } \\
\text { damper }\end{array}$ & $30 \Omega$ & $100 \Omega$ & $200 \Omega$ \\
\hline $\begin{array}{c}\text { Power Spectrum } \\
(\mathrm{Pa})\end{array}$ & 0.099 & 0.110 & 0.087 & 0.094 \\
\hline $\begin{array}{c}\text { Heavy Vehicle } \\
\text { (cars) }\end{array}$ & 278 & 288 & 247 & 282 \\
\hline
\end{tabular}

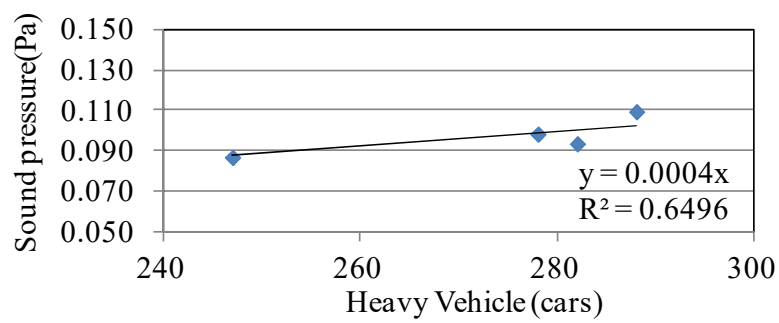

Fig.33 Correlation of total power spectrum between $10 \mathrm{~Hz}$ and $30 \mathrm{~Hz}$ to large-vehicle traffic.

Table 10 Total power spectrum ratio between $3.25 \mathrm{~Hz}$ and $3.5 \mathrm{~Hz}$ to $10 \mathrm{~Hz}$ and $30 \mathrm{~Hz}$.

\begin{tabular}{lcccc}
\hline & $\begin{array}{c}\text { Oil } \\
\text { damper }\end{array}$ & $30 \Omega$ & $100 \Omega$ & $200 \Omega$ \\
\hline$(1) 3.25-3.5 \mathrm{~Hz}$ & 0.720 & 1.254 & 0.712 & 0.802 \\
\hline (2) $10-30 \mathrm{~Hz}$ & 8.304 & 8.728 & 7.383 & 7.961 \\
\hline$(3)$ Ratio & 1.016 & 1.052 & 0.902 & 1.030 \\
\hline$(1) /(2) \times(3)$ & 0.088 & 0.151 & 0.087 & 0.104 \\
\hline
\end{tabular}

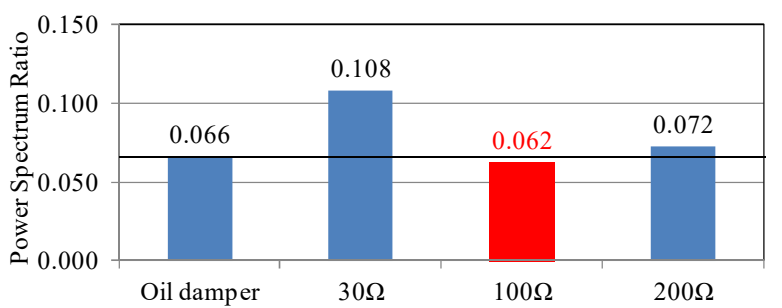

Fig.34 Power spectrum ratio around target eigenfrequency of TMD.

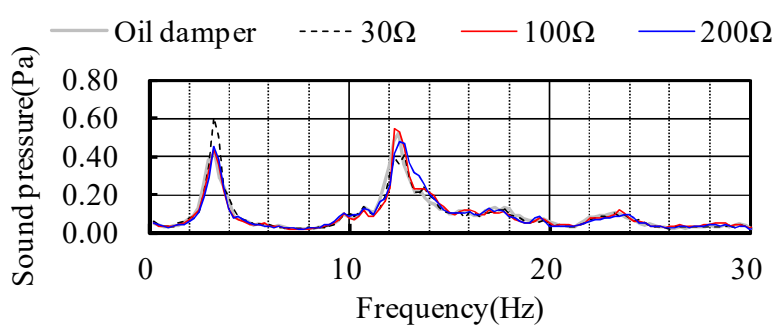

Fig.35 Frequency characteristics of low-frequency noise standardized by large-vehicle traffic volume. 
Table 11 Comparison of power generation characteristics focusing on power generation per resistance $(30,100,200$ $\Omega)$.

\begin{tabular}{|c|c|c|c|c|}
\hline & & $30 \Omega$ & $100 \Omega$ & $200 \Omega$ \\
\hline \multirow{2}{*}{$\begin{array}{l}\text { Power } \\
\text { genera- } \\
\text { tion }\end{array}$} & $\begin{array}{l}\text { Total power } \\
\text { generation }[\mathrm{mWh}]\end{array}$ & 3384.03 & 4574.53 & 3147.71 \\
\hline & $\begin{array}{l}\text { Hourly average } \\
(\mathrm{mWh})\end{array}$ & 27.51 & 27.23 & 18.74 \\
\hline \multirow{2}{*}{$\begin{array}{l}\text { Large- } \\
\text { vehicle } \\
\text { traffic }\end{array}$} & $\begin{array}{l}\text { Total traffic } \\
\text { volume [cars] }\end{array}$ & 51779 & 82959 & 82753 \\
\hline & $\begin{array}{l}\text { Hourly } \\
\text { average [cars/h] }\end{array}$ & 421.0 & 493.8 & 492.6 \\
\hline \multicolumn{5}{|c|}{ Per 1 large-vehicle } \\
\hline \multicolumn{2}{|c|}{$\begin{array}{l}\text { Unit power generation } \\
\text { (Total) }[\mu \mathrm{Wh} / \text { cars }]\end{array}$} & 59.9 & 53.7 & 35.7 \\
\hline
\end{tabular}

seen. Low-frequency noise damping at $100 \Omega$, which aims at reducing the peak vibration level, was equivalent to that of the oil damper.

From the above, we see that the damping effect mostly matches the numerical simulation result, so we can say that it is possible to design the power generation-type TMD in the same way as the ordinallytype TMD.

\section{c) Power generation}

Table 11 shows the amount of electricity generated during the test periods for each electric circuit resistance $30 \Omega, 100 \Omega$, and $200 \Omega$. We used power generation for large-vehicle traffic to compare the amount of power generated for each resistance setting, focusing on the correlation between large-vehicle traffic and bridge-vibration energy. The average power generation per hour per large-vehicle was calculated by dividing power generation per hour by large-vehicle traffic per hour. We define unit power generation as $[\mu \mathrm{Wh} / \mathrm{car}]$. Table 11 shows the average measuring period of unit power generation for each resistance. Comparing unit power generation for each resistance, we see that the unit power generation is maximum at resistance $30 \Omega$, which is the resistance setting aimed for power generation. From this, we see that power generation can be controlled by adjusting resistance settings. This fact was displayed through power generation testing on an actual bridge. The test also verified the usability of the resistance design for power generation-type TMD by numerical simulation.

\section{CONCLUSION}

TMDs are in operation on expressway bridges as an environmental countermeasure. In this study, we proposed a power generation-type TMD using electromagnetic damping devices and carried out road traffic vibration tests on an actual bridge in service to determine the damping effect and amount of power generation. As a result, the following were clarified.

1) We proposed a power generation-type TMD with electromagnetic damping devices that replace oil dampers and carried out tests on road traffic vibration on an actual bridge in service. In the test, we found that the power generation-type TMD was suitable for practical application since the bridge-vibration damping effect and low-frequency reduction effect of TMDs using oil dampers and those of power generation-type TMDs using electromagnetic damping devices, which focused on peak vibration damping, were the same.

2) We found that the electromagnetic damping device may be designed to focus on peak vibration reduction, energy absorption, or power generation by adjusting its electric resistance setting. We also found through power generation tests on an actual bridge that power generation could be adjusted by changing the electric resistance setting, since the unit power generation reached maximum at $30 \Omega$, which was a resistance setting focusing on power generation.

3) By testing on an actual bridge, we found that the power generation-type TMD's capacity in damping bridge-vibration mostly matched the numerical simulation results and low-frequency noise also decreased. This shows that it is possible to design a power generationtype TMD as a measure to control vibration and reduce low-frequency noise of road bridges, like the conventional TMD.

By replacing oil dampers of TMDs installed on bridges, with electromagnetic damping devices to control vibration as an environmental measure, bridge-vibration damping, and low-frequency noise reduction may be managed easily through electromagnetic control. Therefore, depending on the time zone, such as when there is heavy large-vehicle traffic or when environmental issues tend to arise, TMD settings can be adjusted according to the purpose, such as to control bridge-vibration, reduce low-frequency noise, or to generate power. TMDs are installed as an environmental measure, and further improvements may be expected by adding the ability to generate power that can be used to supply power to frequency and damping monitoring systems and also to health monitoring systems, which are considered effective in prolonging the life of a bridge.

ACKNOWLEDGMENT: The experiments of this study were carried out as a joint study of the Tokyo Institute of Technology, Nippon Expressway Research Institute Company Limited, Tokkyokiki Corp- 
oration, SUBARU Enterprise Company Limited, and ITM Company Limited. We would like to thank all those who cooperated or participated in the tests, data analysis, and examinations of the results.

\section{REFERENCES}

1) Tokunaga, N., Fukushima, A. and Nishimura, A.: Study on acoustic characteristics of low-frequency noise generated from elevated roads, Committee of Infrastructure Planning and Management Papers, No. 17, 2000.

2) Kawada, N. and Kawatani, M.: Theoretical analysis of lowfrequency noise caused by road bridge traffic vibration by the boundary element method, Japan Society of Civil Engineers Papers A, Vol. 62, No. 3, pp. 702-712, 2006.

3) Osafune, T. and Yamamoto, M.: Noise and vibration measures for highway bridges, Bridge and Foundation Engineering, November 2011 Issue, 2011.

4) Fukada, S.: Countermeasure technology for vibration and low-frequency noise of bridge generated by travelling vehicles, Souonseigyo (noise control), Vol. 40, No. 2, pp. 61-64, 2016.

5) Murai, T.: Experiment on bridge vibration and low -frequency noise reduction of TMD on an actual bridge, Bridges Vibration Colloquium, '01 Papers, 2001.

6) Mikami, S., Takagi, Y., Yamazaki, T., Tubota, Y. and Oshima, T.: Study on changes of vibrational characteristics of bridge in service for seven years, Japan Society of Civil Engineers Hokkaido Branch Papers and Reports, Vol. 62, pp. 61-62, 2005.

7) Kaito, K., Abe, M., Fujino, Y. and Kumasaka, K.: Void detection of concrete structure focusing on local vibration characteristics, Japan Society of Civil Engineers Papers, No. 690/V-53, pp. 121-132, 2001.

8) Fukada, S., Muroi, N., Momiyama, Y. and Kajikawa, Y.:
Effects of cyclic road surface on bridge evaluated from longterm monitoring before and after road repair, Japan Society of Civil Engineers Papers A1, Vol. 67, No. 1, pp. 121-136, 2011.

9) Abe, A. and Fujino, Y.: Efficiency and design formulas of multiple-tuned mass damper (MTMD), Japan Society of Civil Engineers Papers, No. 465/I-23, pp. 87-96, 1993.

10) Abe, M. and Fujino, Y.: Formula for performance evaluation of multiple-tuned mass damper (MTMD), Japan Society of Civil Engineers Papers, No. 465/I-23, pp. 97-106, 1993.

11) Yoshinaka, S. and Kawaguchi, K.: Study on distributed TMD based on MMD method for multiple-mode control in large-span structures, Architectural Institute of Japan Structural System Papers, Vol. 586, pp. 123-130, 2004.

12) Takeya, K., Sasaki, E., Iwabuki, H., Osafune, T., Hora, H. and Nagoya, T.: Development of tuned mass-based power generation device for bridge vibration and its application to real bridges, Japan Society of Civil Engineers Papers A1, Vol. 72, No. 2, pp. 290-301, 2016.

13) Tokkyokiki Corporation, http://www.tokkyokiki.co.jp/pdf new/tokkyokiki_catalog 54\%20md.pdf, 2017.10.1.

14) Takeya, K. and Sasaki, E.: Study on structure type and design of the tuned mass-based power generation device for bridge vibration, Japan Society of Civil Engineers Papers A1, Vol. 71, No. 2, pp. 267-276, 2015.

15) Taguchi, N., Hanasato, T. and Ishida, R.: Study on excitation force characteristics of road traffic vibration and prediction method of environmental ground vibration, Architectural Institute of Japan Environment Papers, Vol. 73, No. 633, pp. 1241-1247, 2008.

(Received December 12, 2019)

(Accepted December 26, 2019) 